\title{
Genetic Variation in the ABCB1 Gene May Lead to mRNA Level Chabge: Application to Gastric Cancer Cases
}

\author{
Maryam Mansoori' ${ }^{1}$, Masoud Golalipour ${ }^{1,2}$, Shahriar Alizadeh ${ }^{3}$, Ataollah \\ Jahangirerad $^{4}$,Seyed Reza Khandozi ${ }^{4}$, Habibollah Fakharai ${ }^{5}$, Majid Shahbazi ${ }^{1 *}$
}

\begin{abstract}
Background: One of the major mechanisms for drug resistance is associated with altered anticancer drug transport, mediated by the human-adenosine triphosphate binding cassette (ABC) transporter superfamily proteins. The overexpression of adenosine triphosphate binding cassette, sub-family B, member 1 (ABCB1) by multidrug-resistant cancer cells is a serious impediment to chemotherapy. In our study we have studied the possibility that structural single-nucleotide polymorphisms (SNP) are the mechanism of ABCB1 overexpression. Materials and Methods: A total of 101 gastric cancer multidrug resistant cases and 100 controls were genotyped with sequence-specific primed PCR (SSP-PCR). Gene expression was evaluated for 70 multidrug resistant cases and 54 controls by real time PCR. The correlation between the two groups was based on secondary structures of RNA predicted by bioinformatics tool. Results: The results of genotyping showed that among 3 studied SNPs, rs28381943 and rs2032586 had significant differences between patient and control groups but there were no differences in the two groups for C3435T. The results of real time PCR showed over-expression of ABCB1 when we compared our data with each of the genotypes in average mode. Prediction of secondary structures in the existence of 2 related SNPs (rs28381943 and rs2032586) showed that the amount of $\Delta G$ for original $m R N A$ is higher than the amount of $\Delta G$ for the two mentioned SNPs. Conclusions: We have observed that 2 of our studied SNPs (rs283821943 and rs2032586) may elevate the expression of ABCB1 gene, through increase in mRNA stability, while this was not the case for C3435T.
\end{abstract}

Keywords: Gastric cancer - variation - ABCB1 gene - real time PCR - multidrug resistance (MDR) - over-expression

Asian Pac J Cancer Prev, 16 (18), 8467-8471

\section{Introduction}

The development of multidrug resistance (MDR) to chemotherapy remains a major challenge in the treatment of cancer (Ullah, 2008; Ren et al., 2012; Zhu et al., 2013). Resistance exists against every effective anticancer drug and can develop by numerous mechanisms including decreased drug uptake, increased drug efflux, activation of detoxifying systems, activation of DNA repair mechanisms, evasion of drug-induced apoptosis, etc.(Sonneveld, 2000; Wu et al., 2014). One of the major mechanisms for drug resistance is associated with altered anticancer drug transport, mediated by members of the $\mathrm{ABC}$ transporter superfamily proteins including $\mathrm{ABCB} 1$ gene (Golalipour et al., 2007; Oliveira et al., 2014).

$\mathrm{ABCB} 1$, the first discovered $\mathrm{ABC}$ transporter, is expressed in various tissues to protect them from the adverse effect of toxins (Fung and Gottesman, 2009). The properties ABCB1 expression have been extensively studied in cancer (Juliano and Ling, 1976; Wallner et al., 1993; Sonneveld, 2000; Felipe et al., 2014). Patients with high expression of ABCB1 at diagnosis may be predisposed to mutation development. Furthermore, increasing expression of $\mathrm{ABCB} 1$ over time may be contributing to acquiring drug resistance. ABCB 1 activation may be an important prognostic marker, and potential target for pharmacological manipulation (Deborah et al., 2006). Different mechanisms proposed for $\mathrm{ABCB} 1$ over-expression including Mutation, Aneuploidy (rearrangements and gene amplification) and SNPs (including SNPs in promoter and structural SNPs in RNA) (Baker and El-Osta, 2003; Wang et al., 2006; Mahjoubi et al., 2008; Fung and Gottesman, 2009; Wang et al., 2009). Gene amplification is also described in some cellular models but it seems to be uncommon in clinical species (Roninson et al., 1991; Golalipour et al., 2007).

In the present study we have investigated the possible role of structural SNP in the over-expression of the ABCB1 gene. There is only one report of applying SNPs with the structural view for the ABCB1 gene that potentially have

${ }^{1}$ Medical Cellular \& Molecular Research Center Talghani Children Hospital of Golestan University of Medical Sciences, Bolv Janbazan, ${ }^{2}$ Department of Medical Genetics,Faculty of Advanced Medical Technologies, Golestan University of Medical Sciences, Gorgan, Iran, ${ }^{3}$ Pathology Laboratory, Hakim Jorjani Hospital, ${ }^{4}$ Oncology Department, 5 th Golestan University Hospital, Gorgan, Iran, ${ }^{5}$ Novarx Corporation, San Diego, USA *For correspondence: Shahbazimajid@yahoo.co.uk 
an effect on performance (Fung and Gottesman, 2009). As a result of the paucity of SNP polymorphism in the processing locations in literature, we have assessed SNPs polymorphism in splicing site, including rs28381943 and rs2032586. We also included C3435T, located in exon 26 , which is commonly used in different studies and has shown different frequencies of polymorphisms that vary significantly in different ethnicities (Gow et al., 2008; Andersen et al., 2009; Fung and Gottesman, 2009).

\section{Materials and Methods}

\section{Samples}

Seventy fresh peripheral blood samples were collected from patients with gastric cancers (including esophageal, colon, stomach and rectum) treated with 5FU and as a control 100 blood samples were collected from healthy controls that did not have a history of cancers $(10 \mathrm{ml}$ from each person which, collected in falcon tubes that contained EDTA). In addition 31 tissue samples were collected from paraffin embedded tissue blocks of patients with the mentioned cancers (gastric cancers).

\section{DNA and RNA extraction.}

DNA is extracted using the phenol-chloroform method. The PMBC (Peripheral blood mononuclear cell) was separated using ficole. The PMBC was then cultured in an RPMI-1640 medium and cells were stimulated to divide with PMA and LPS. After 72 hours RNA was extracted from cultured cells by TRIZOL based method. The isolated RNA was used to synthesize cDNA using Fermentase kit of first strand cDNA synthesis.

\section{Genotyping}

Genotyping was done with SSP-PCR (Sequence Specific Primer) for 101 cancer cases and the 100 control group. Primers for SSP-PCR were designed with primer3 software (Table 1). Human Growth Hormone (HGH) primers were used as a control to check the results of SSP-PCR.

\section{ABCB1 mRNA quantification}

The amount of gene expression was measured using Relative Quantitative Real Time PCR (ABI 7300) for all 101 cancer cases and 100 controls. These primers were used for Real Time PCR: Forward: 5' GAGCCCATCCTGTTGACTG 3' and Reverse: 5' ACTATAGGCCAGAGAGGCTGC 3'(Song et al., 2002). 18 srRNA was used as an internal control.

\section{RNA structure prediction and statistical analysis}

To check the effect of our SNPs on mRNA structure, the Vienna RNA fold web servers (http://rna.tbi.univie. ac.at/) were used to predict the secondary structures of RNA and its folding based on MFE (Minimum Free Energy). This database predicted the amount of $\Delta \mathrm{G}$ for the requested sequences with the knowledge that there is an inverse correlation between the $\Delta \mathrm{G}$ and the stability of the molecules. Statistical calculations and tests were performed using the SPSS 16.0 software (SPSS, Inc., Chicago, IL). Normality of data was tested using the
Shapiro-Wilk normality test. Differences between groups were analyzed by one-way ANOVA and the limit of statistical significance was defined as $\mathrm{p}<0.05$.

\section{Results}

rs28381943 and rs2032586 genotypic frequencies

A total number of 201 cases were classified in two different groups; Cancer patients cases $(\mathrm{N}=101)$, and healthy control individuals with no history of cancer $(\mathrm{N}=100)$. ABCB1 polymorphism at positions rs28381943, rs2032586 and C3435T were determined and the distribution of genotypes in cancer cases and healthy controls were compared. Also the genotyping analysis was done for tissue samples to support and increase the sample size for polymorphism determination. These results are presented in Tables 2-7.

The results of genotyping showed that there is a significant difference in both genotypic and allelic frequencies for rs28381943 SNP between the cancer subjects and the control group. For rs2032586 there is no significant difference in allelic frequencies while there existed a significant difference in the genotypic frequencies between two groups.

For the C3435T position we have not seen any differences between the cancer subjects and the control group either in the allelic or genotypic frequencies. The cancer subjects showed significant genotypic frequency differences for both $\mathrm{A} / \mathrm{G}$ and $\mathrm{G} / \mathrm{G}$ genotypes for rs2032586. Also, for rs28381943 a significant difference in the $\mathrm{G} / \mathrm{G}$ genotype is presented. The differences which were observed in genotypes between tumoral and normal tissue samples of a person may be because of lack of control on DNA replication or mutations which occurs in tumoral development.

\section{$m R N A$ level increased in mutated genotype}

The results of Real Time PCR showed an overexpression of ABCB1 when we compared our data with each genotypes in average mode. The results of the evaluation of ABCB1 expression are presented in Chart 1 and Chart 2.

Mutated mRNA have lower $\Delta G$ compared to original mRNA

Table 1. Primer Sequences used for the ABCB1 Gene in Positions C3435T, rs28381943 and rs2032586 for Sequence-Specific Primer Genotyping Method

\begin{tabular}{ll}
\hline Primer Sequence & Primer Position \\
\hline 5' GTGGTGTCACAGGAAGAGGTT 3' $^{\prime}$ & C3435T T \\
5' GTGGTGTCACAGGAAGAGGTC 3' & C3435T C \\
5' ACTAATAGGCCAGAGAGGCTGC 3' & Generic \\
5' CGATCCATGCTCAGACAGGTA 3' & rs28381943 A \\
5' CGATCCATGCTCAGACAGGTG 3' & rs28381943 G \\
5' TTCAACCGCATCTCTGACGT 3' & Generic \\
5' GTTCAGACCCTTCAAGATCTACA 3' & rs2032586 A \\
5' TTCAGACCCTTCAAGATCTACG 3' & rs2032586 G \\
5' ACTTCAGTTACCCATCTCGAA 3' & Generic \\
5-GCCTTCCCAACCATTCCCTTA-3 & HGH (sense) \\
5-TCACGGATTTCTGTTGTGTTTC-3 & HGH (antisense) \\
\hline
\end{tabular}


Genetic Variation in the ABCB1 Gene May Lead to mRNA Level Change: Application in Gastric Cancer Cases Table 2. The Genotypic and Allelic Frequency Distribution for rs28381943 in ABCB1 Gene in Blood Samples

\begin{tabular}{lccccc}
\hline Genotype & Subjects (\%) & Control $(\%)$ & P & OR & 95 CI \% \\
\hline A/A & $35(42.7 \%)$ & $47(57.3 \%)$ & 1 & - & - \\
A/G & $46(49.5 \%)$ & $47(50.5 \%)$ & 0.014 & 3.4057 & $0.089-0.854$ \\
G/G & $20(76.9 \%)$ & $6(23.1 \%)$ & 0.003 & 4.476 & $0.067-0.662$ \\
Allele"A" & $116(57.42 \%)$ & $141(70.5 \%)$ & 1 & - & - \\
Allele"G" & $86(42.57 \%)$ & $59(29.5 \%)$ & 0.007 & 1.7717 & $0.365-0.870$ \\
\hline
\end{tabular}

$\mathrm{OR}=$ odds ratio. $\mathrm{CI}=95 \%$ Confidence Interval of the odds ratio. $\mathrm{P}=\mathrm{p}$-value

Table 3. The Genotypic and Allelic Frequency Distribution for rs2032586 in ABCB1 Gene in Blood Samples

\begin{tabular}{lccccc}
\hline Genotype & Subjects $(\%)$ & Control $(\%)$ & P & OR & 95 CI \% \\
\hline A/A & $61(53 \%)$ & $54(47 \%)$ & 1 & - & - \\
A/G & $22(31 \%)$ & $49(69 \%)$ & 0.001 & 11.878 & $0.015-0.346$ \\
G/G & $16(84.2 \%)$ & $3(15.8 \%)$ & 0.01 & 4.721 & $0.038-0.806$ \\
Allele"A" & $144(72.73 \%)$ & $157(74.06 \%)$ & 1 & - & - \\
Allele"G" & $54(27.27 \%)$ & $55(25.94 \%)$ & 0.82 & 0.934 & $0.588-1.484$ \\
\hline
\end{tabular}

$\mathrm{OR}=$ odds ratio. $\mathrm{CI}=95 \%$ Confidence Interval of the odds ratio. $\mathrm{P}=\mathrm{p}$-value

Table 4. The Genotypic and Allelic Frequency Distribution for C3435T in ABCB1 Gene in Blood Samples

\begin{tabular}{|c|c|c|c|c|c|}
\hline Genotype & Subjects (\%) & Control (\%) & $\mathrm{P}$ & OR & $95 \mathrm{CI} \%$ \\
\hline$\overline{\mathrm{C} / \mathrm{C}}$ & $23(63.9 \%)$ & $13(36.1 \%)$ & 1 & - & - \\
\hline $\mathrm{C} / \mathrm{T}$ & $56(44.8 \%)$ & $69(55.2 \%)$ & 0.475 & 0.738 & $0.344-1.58$ \\
\hline $\mathrm{T} / \mathrm{T}$ & $22(52.4 \%)$ & $20(47.6 \%)$ & 0.3618 & 1.608 & $0.59-4.43$ \\
\hline Allele"C"' & $102(50.50 \%)$ & $95(46.57 \%)$ & 1 & - & - \\
\hline Allele"T"' & $100(49.5 \%)$ & $109(53.43 \%)$ & 0.487 & 1.17 & $0.778-1.76$ \\
\hline
\end{tabular}

$\mathrm{OR}=$ odds ratio $. \mathrm{CI}=95 \%$ Confidence Interval of the odds ratio. $\mathrm{P}=\mathrm{p}$-value

Table 5. The Genotypic and Allelic Frequency Distribution for C3435T in ABCB1 Gene in Blood Samples

\begin{tabular}{lccccc}
\hline Genotype & Subjects (\%) & Control (\%) & P & OR & 95 CI \% \\
\hline C/C & $4(12.9 \%)$ & $5(15.6 \%)$ & 1 & - & - \\
C/T & $19(61.3 \%)$ & $19(59.4 \%)$ & 0.5288 & 0.8 & $0.137-4.393$ \\
T/T & $8(25.8 \%)$ & $8(25.0 \%)$ & 0.6168 & 1 & $0.264-3.782$ \\
Allele"C" & $27(43.55 \%)$ & $29(45.31 \%)$ & 1 & - & - \\
Allele"T" & $35(56.45 \%)$ & $35(54.69 \%)$ & 0.492 & 0.931 & $0.434-1.995$ \\
\hline OR= odds ratio. CI= 95\% Confidence Interval of the odds ratio. P= p-value & &
\end{tabular}

Table 6. The Genotypic and Allelic Frequency Distribution for rs2032586 in ABCB1 Gene in Blood Samples

\begin{tabular}{|c|c|c|c|c|c|}
\hline Genotype & Subjects (\%) & Control (\%) & $\bar{P}$ & $\overline{\mathrm{OR}}$ & $95 \mathrm{CI} \%$ \\
\hline$\overline{\mathrm{A} / \mathrm{A}}$ & $4(13.8 \%)$ & $5(16.7 \%)$ & 1 & - & - \\
\hline $\mathrm{A} / \mathrm{G}$ & $15(51.7 \%)$ & $18(60.0 \%)$ & 0.6286 & 0.96 & $0.159-5.395$ \\
\hline $\mathrm{G} / \mathrm{G}$ & $10(34.5 \%)$ & $7(23.3 \%)$ & 0.2756 & 0.583 & $0.149-2.216$ \\
\hline Allele"A" & $23(39.65 \%)$ & $28(46.66 \%)$ & 1 & - & - \\
\hline Allele"G" & $35(60.35 \%)$ & $32(53.34 \%)$ & 0.28 & 0.751 & $0.338-1.660$ \\
\hline
\end{tabular}

$\mathrm{OR}=$ odds ratio. $\mathrm{CI}=95 \%$ Confidence Interval of the odds ratio. $\mathrm{P}=\mathrm{p}$-value

Table 7. The Genotypic and Allelic Frequency Distribution for rs28381943 in ABCB1 Gene in Blood Samples

\begin{tabular}{lccccc}
\hline Genotype & Subjects $(\%)$ & Control $(\%)$ & P & OR & 95 CI \% \\
\hline AA/A & $11(35.5 \%)$ & $11(34.4 \%)$ & 1 & - & - \\
A/G & $14(45.2 \%)$ & $11(34.4 \%)$ & 0.4528 & 0.785 & $0.213-2.882$ \\
G/G & $6(19.4 \%)$ & $10(31.2 \%)$ & 0.202 & 2.121 & $0.496-9.410$ \\
Allele"A" & $36(58.06 \%)$ & $33(51.56 \%)$ & 1 & - & - \\
Allele"G" & $26(41.94 \%)$ & $31(48.44 \%)$ & 0.289 & 1.3 & $0.607-2.791$ \\
\hline
\end{tabular}

$\mathrm{OR}=$ odds ratio. $\mathrm{CI}=95 \%$ Confidence Interval of the odds ratio. $\mathrm{P}=\mathrm{p}$-value

ABCB1 mRNA structure $\Delta \mathrm{G}$ is $-1586.68 \mathrm{kcal} / \mathrm{mol}$. The amount of $\Delta \mathrm{G}$ in $\mathrm{rs} 28381943$ is $-2482.30 \mathrm{kcal} / \mathrm{mol}$. rs28381943 may cause disruption in the splicing process, resulting in the observation of intron 19 that is usually deleted through normal splicing. Also rs2032586 may cause disruption in the splicing process, resulting in the inclusion of intron 11 that is usually deleted through normal splicing. The amount of $\Delta \mathrm{G}$ is $-1634.12 \mathrm{kcal} / \mathrm{mol}$. 


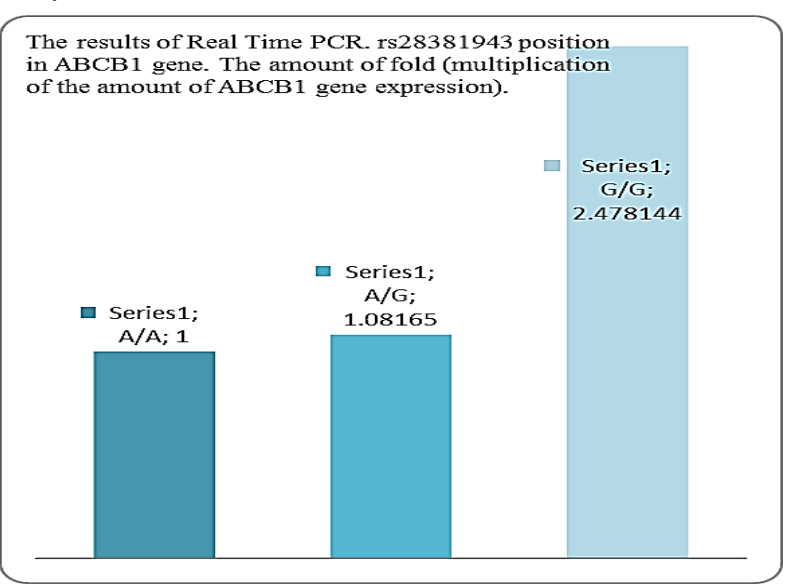

Figure 1. The Results of Real Time PCR. The amount of fold (multiplication of the amount of ABCB1 gene expression)

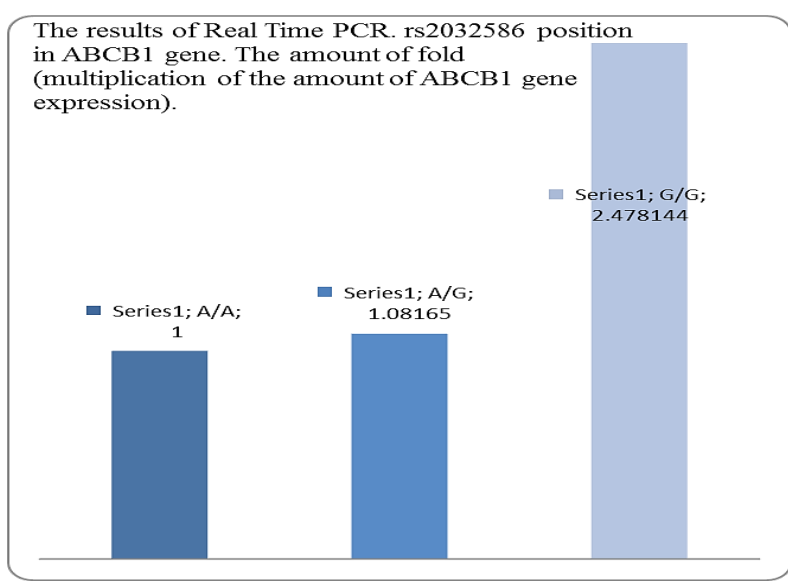

Figure 2. The Results of Real Time PCR. The amount of fold (multiplication of the amount of ABCB1 gene expression)

\section{Discussion}

Our data suggests that rs283821943 and rs2032586 SNPs may be the reason for the over-expression of the ABCB1 gene because of the significant differences which were observed among genotypes. Our results showed that GG allele has higher mRNA level compared to AA allele. The expression of the ABCB1 gene in the existence of these SNPs is higher than normal. On the other hand, we have shown that the existence of these SNPs may lead to the stabilization of ABCB1 mRNA causing the ABCB1 gene to become overexpressed. The amount of $\Delta \mathrm{G}$ for ABCB $1 \mathrm{mRNA}$ is $-1586.68 \mathrm{kcal} / \mathrm{mol}$ which is lower than $-2482.30 \mathrm{kcal} / \mathrm{mol}$ for $\mathrm{ABCB} 1 \mathrm{mRNA}$ in the case of rs28381943 SNP existence and also -1634.12kcal/ mol for ABCB1 mRNA in the case of rs2032586 SNP existence. As previous studies represent (Wu et al., 2014), C3435T position has not shown any differences between case and control group neither in allelic frequencies nor in genotypic frequencies. Our data suggest that SNPs in splicing position may be a place of more experiments to reveal if they may be the reason for mRNA stabilization leading to gene overexpression.

\section{Acknowledgements}

We would like to thank Research Council of Golestan University of Medical Sciences for funding and a great thank from Dr. Habib Fakhrai the Chief Scientific Officer of NOVARX corporation- USA, Oncology and Shafa department of 5 Azar hospital-Golestan Province in Iran.

\section{References}

Andersen V, Ostergaard M, Christensen J, et al (2009). Polymorphisms in the xenobiotic transporter Multidrug Resistance 1 (MDR1) and interaction with meat intake in relation to risk of colorectal cancer in a Danish prospective case-cohort study. BMC Cancer, 9, 407.

Baker EK, El-Osta A (2003). The rise of DNA methylation and the importance of chromatin on multidrug resistance in cancer. Exp Cell Res, 290, 177-94.

de Oliveira J, Felipe AV, Neto RA, et al (2014). Association between ABCB1 immunohistochemical expression and overall survival in gastric cancer patients. Asian Pac J Cancer Prev, 15, 6935-8.

Deborah White, Phuong Dang, Amity Venables, et al (2006). $\mathrm{ABCB} 1$ overexpression may predispose imatinib treated $\mathrm{cml}$ patients to the development of Abl kinase domain mutations, and may be an important contributor to acquired resistance. Blood, 108.

Felipe AV, Moraes AA, de Oliveira J, et al (2014). Establishment and partial characterization of an epirubicin-resistant gastric cancer cell line with upregulated ABCB1. Asian Pac J Cancer Prev, 15, 6849-53.

Fung KL, Gottesman MM (2009). A synonymous polymorphism in a common MDR1 (ABCB1) haplotype shapes protein function. Biochim Biophys Acta, 1794, 860-71.

Golalipour M, Mahjoubi F, Sanati MH, et al (2007). Gene dosage is not responsible for the upregulation of MRP1 gene expression in adult leukemia patients. Arch Med Res, 38, 297-304.

Gow JM, Hodges LM, Chinn LW, et al (2008). Substratedependent effects of human ABCB1 coding polymorphisms. $J$ Pharmacol Exp Ther, 325, 435-42.

Juliano RL, Ling V (1976). A surface glycoprotein modulating drug permeability in Chinese hamster ovary cell mutants. Biochim Biophys Acta, 455, 152-62.

Mahjoubi F, Golalipour M, Ghavamzadeh A, et al (2008). Expression of MRP1 gene in acute leukemia. Sao Paulo Med J, 126, 172-9.

Ren YQ, Han JQ, Cao JB, et al (2012). Association of MDR1 gene polymorphisms with susceptibility to hepatocellular carcinoma in the Chinese population. Asian Pac J Cancer Prev, 13, 5451-4.

Roninson IB, Pastan I, Gottesman MM (1991). Isolation and characterization of the human MDR (P-glycoprotein) genes. In 'Molecular and Cellular Biology of Multidrug Resistance in Tumor Cells', Eds Springer, 91-106

Song P, Li S, Meibohm B, et al (2002). Detection of MDR1 single nucleotide polymorphisms C3435T and G2677T using realtime polymerase chain reaction: MDR1 single nucleotide polymorphism genotyping assay. AAPS PharmSci, 4, 29.

Sonneveld P (2000). Multidrug resistance in haematological malignancies. J Intern Med, 247, 521-34.

Ullah MF (2008). Cancer multidrug resistance (MDR): a major impediment to effective chemotherapy. Asian Pac J Cancer Prev, 9, 1-6.

Wallner J, Depisch D, Gsur A, et al (1993). MDR1 gene expression and its clinical relevance in primary gastric carcinomas. Cancer, 71, 667-71.

Wang Z, Sew PH, Ambrose H, et al (2006). Nucleotide sequence 
Genetic Variation in the ABCB1 Gene May Lead to mRNA Level Change: Application in Gastric Cancer Cases analyses of the MRP1 gene in four populations suggest negative selection on its coding region. BMC Genomics, 7, 111 .

Wang Z, Wang J, Chong S, et al (2009). Mining potential functionally significant polymorphisms at the ATP-bindingcassette transporter genes. Current Pharmacogenomics and Personalized Medicine (Formerly Current Pharmacogenomics), 7, 40-58.

Wu DD, Zhang JX, Li J, et al (2014). Lack of association of the MDR1 C3435T polymorphism with susceptibility to gastric cancer and peptic ulcer: a systemic review and meta-analysis. Asian Pac J Cancer Prev, 15, 3021-7.

Zhu CY, Lv YP, Yan DF, et al (2013). Knockdown of MDR1 increases the sensitivity to adriamycin in drug resistant gastric cancer cells. Asian Pac J Cancer Prev, 14, 6757-60. 